\title{
Assessment of Bone Quality by Quantitative Ultrasound of Proximal Phalanges of the Hand and Fracture Rate in Children and Adolescents with Bone and Mineral Disorders
}

\author{
GIAMPIERO IGLI BARONCELLI, GIOVANNI FEDERICO, SILVANO BERTELLONI, \\ FEDERICA SODINI, FRANCESCA DE TERLIZZI, RUGGERO CADOSSI AND GIUSEPPE SAGGESE \\ Endocrine Unit, Division of Pediatrics, Department of Reproductive Medicine and Pediatrics, University \\ of Pisa, Pisa, IT-56125, Italy [G.I.B., G.F., S.B., F.S., G.S.]; and IGEA Biophysics Laboratory, Carpi, \\ Modena, IT-41012, Italy [F.D.T., R.C.]
}

\section{ABSTRACT}

Bone quality by quantitative ultrasound and fracture rate were assessed in 135 (64 males) children and adolescents aged 3-21 y with bone and mineral disorders such as chronic anticonvulsants or glucocorticoids treatment, juvenile rheumatoid arthritis, celiac disease, paucity of intrahepatic bile ducts, autoimmune hepatitis, genetic diseases, idiopathic juvenile osteoporosis, disuse osteoporosis, $\beta$-thalassemia major, survivors of acute lymphoblastic leukemia, liver transplantation, calcium deficiency, and nutritional or X-linked hypophosphatemic rickets. Amplitude-dependent speed of sound through the distal end of the first phalangeal diaphysis of the last four fingers of the hand was measured by an ultrasound device. In the majority of patients cortical area to total area ratio by metacarpal radiogrammetry $(n=120)$ and lumbar bone mineral density (BMD) by dual-energy x-ray absorptiometry $(n=99)$ were also assessed. In patients with X-linked hypophosphatemic rickets radial BMD by single-photon absorptiometry instead of lumbar BMD was measured. Mean values of amplitude-dependent speed of sound, cortical area to total area ratio, lumbar BMDarea, or lumbar BMD corrected for bone sizes estimated by a mathematical model (BMDvolume), as well as mean values of radial BMD in patients with X-linked hypophosphatemic rickets, expressed as z score, were significantly reduced $(p<0.0001)$ in comparison with their reference values $(-1.7 \pm 1.0,-2.0 \pm 0.9,-3.0 \pm 1.3,-1.9 \pm 1.0,-2.7 \pm 0.7$, respectively). A positive relationship was found between amplitudedependent speed of sound and cortical area to total area ratio $(r=$ $0.90, p<0.0001)$, lumbar BMDarea $(r=0.62, p<0.0001)$, or lumbar BMDvolume $(r=0.66, p<0.0001)$. Fifty-two patients
$(38.5 \%)$ had suffered fractures in the 6 mo preceding the bone measurements, the radial distal metaphysis being the most frequent fracture site (28.8\%). Mean values of amplitude-dependent speed of sound, cortical area to total area ratio, lumbar BMDarea, or lumbar BMDvolume, expressed as $\mathrm{z}$ score, of fractured patients were significantly lower $(p<0.0001)$ than those of fracture-free patients $(-2.2 \pm 1.0$ and $-1.4 \pm 0.8,-2.6 \pm 0.9$ and $-1.7 \pm 0.7,-3.5 \pm$ 1.2 and $-2.5 \pm 1.0,-2.5 \pm 1.0$ and $-1.3 \pm 0.7$, respectively). Phalangeal quantitative ultrasound may be a useful method to assess bone quality and fracture risk in children and adolescents with bone and mineral disorders. (Pediatr Res 54: 125-136, 2003)

$\quad$ Abbreviations
AD-SoS, amplitude-dependent speed of sound
BMI, body mass index
BMC, bone mineral content
BMD, bone mineral density
CA, cortical area
CV, coefficient of variation
DXA, dual-energy x-ray absorptiometry
25-OH-D, 25-hydroxyvitamin D
MA, medullary cavity area
MW, medullary cavity width
QUS, quantitative ultrasound
ROI, region-of-interest
TA, total area
TW, total subperiosteal width

DXA has been widely accepted as a noninvasive method for BMD measurement in adults as well as in pediatric subjects (1). An important shortcoming of DXA is that it measures an areal

Received April 26, 2002; accepted November 22, 2002.

Correspondence: Giampiero I. Baroncelli, M.D., Endocrine Unit, Division of Pediatrics, Department of Reproductive Medicine and Pediatrics, University of Pisa, IT-56125, Pisa, Italy; e-mail: g.baroncelli@clp.med.unipi.it

DOI: 10.1203/01.PDR.0000069845.27657.EB density, so that in growing children BMD is closely related to anthropometric findings and bone sizes (2). Correction of the amount of mineral measured for the apparent bone sizes (BMDvolume) may be a useful tool to reduce the large biologic variation in BMD measurements caused mainly by the confounding influence of age-related changes in bone geometry (2-4).

Bone mass studies have recently revitalized the use of metacarpal radiogrammetry to assess cortical bone mass and fracture risk (5-7). Indeed, changes in cortical width show a 
higher degree of correlation with changes in mass and strength of cortical bone $(8,9)$. A limitation of metacarpal radiogrammetry may be that it does not measure trabecular bone, and most metabolic bone diseases affect trabecular bone to a greater extent than cortical bone (9), but a reduction in bone mass may occur equally in both trabecular and cortical bone and not selectively in either (8).

QUS is a new and noninvasive method of estimating bone quality $(10-12)$. This technique is safe, easy to use, and radiation-free; the equipment is portable and relatively cheap in comparison with more expensive densitometric techniques such as DXA and quantitative computed tomography. Clinical studies showed that phalangeal QUS was able to discriminate between osteoporotic and healthy women (12-15), and it may predict fracture independent of BMD $(12,16)$. The U.S. Food and Drug Administration has recently approved the use of some QUS devices for the routine diagnosis of bone mineral status and determination of fracture risk (17). There are very few data on the assessment of phalangeal QUS in children with bone and mineral disorders $(18,19)$.

In this study we assessed AD-SoS at proximal phalanges of the hand in children and adolescents with bone and mineral disorders to investigate the application of phalangeal QUS in clinical practice. In the majority of patients we also assessed cortical bone mass by metacarpal radiogrammetry and lumbar BMD by DXA to examine their relationship with phalangeal QUS. In addition, we assessed whether phalangeal QUS was able to discriminate fractured from fracture-free patients.

\section{METHODS}

Patients. A total of 135 patients (64 males and 71 females) aged 3-21 y with bone and mineral disorders were recruited from our Endocrine Unit at the Department of Pediatrics of our university. The examined disorders and clinical findings of patients are reported in Table 1.

Patients receiving chronic anticonvulsant treatment (phenobarbital, phenytoin, primidone, or carbamazepine in various combinations) were affected by idiopathic epilepsy, with an otherwise normal neurologic status. The duration of treatment was more than 15 mo up to $4 \mathrm{y}$. No patient received vitamin D supplements during the anticonvulsant treatment, and all of them had reduced serum $25-\mathrm{OH}-\mathrm{D}$ levels $(23.2 \pm 4.2 \mathrm{nM}$; normal values, $28-110 \mathrm{nM} ; p<0.001$ ).

Patients receiving long-term glucocorticoid treatment (maintenance dose, $0.3-0.9 \mathrm{mg}$ prednisone $/ \mathrm{kg}$ per day) were affected by hematic disorders such as autoimmune hemolytic anemia ( $n$ $=6)$ or immune thrombocytopenic purpura $(n=3)$, severe asthma $(n=3)$, or sarcoidosis $(n=1)$. Duration of glucocorticoid treatment ranged from 1.2 to $1.9 \mathrm{y}$.

Patients with juvenile rheumatoid arthritis had a pauciarticular $(n=4)$ or a polyarticular $(n=5)$ form of the disease, but no patient showed involvement of the small joints of the hand at entry into the study. Disease duration ranged from 2.3 to 7.7 y. Three patients had received systemic glucocorticoid treatment ( $1 \mathrm{mg}$ prednisone/kg per day) for 2-7 mo during the year preceding the study, but at entry no patient was receiving glucocorticoids.

All patients with celiac disease were newly diagnosed. The patients were observed for short stature or abdominal symptoms.

Patients affected by paucity of intrahepatic bile ducts had a nonsyndromic form of the disease. All patients received cholestyramine (12-14 g/d) combined with ursodeoxycholic acid $(15-20 \mathrm{mg} / \mathrm{kg}$ per day, $n=4)$ to treat pruritus and jaundice. In addition, a low-fat diet, and supplements of vitamin A, D, E, and $\mathrm{K}$ were given to all patients.

Patients with autoimmune hepatitis were receiving a maintenance dose of prednisone $(0.2-0.4 \mathrm{mg} / \mathrm{kg}$ per day). At entry into the study all patients had aminotransferase values in the normal range. No other autoimmune disorder was associated with autoimmune hepatitis. Three patients had reduced serum 25-OH-D levels $(21.1 \pm 2.1 \mathrm{nM}, p<0.001)$.

Patients with genetic disease were affected by osteogenesis imperfecta $(n=4)$, Marfan syndrome $(n=2)$, Lujan-Fryns syndrome $(n=1)$, and cystic fibrosis $(n=2)$. Except for patients with cystic fibrosis who were receiving vitamin D

Table 1. Examined bone and mineral disorders and clinical findings of patients

\begin{tabular}{|c|c|c|c|c|c|}
\hline Disorder & $n$ & Sex $*$ & $\begin{array}{c}\text { Chronologic age } \\
\text { (y) }\end{array}$ & $\begin{array}{l}\text { Height } \\
\text { (z score) }\end{array}$ & $\begin{array}{c}\text { BMI } \\
\text { (z score) }\end{array}$ \\
\hline Chronic anticonvulsant treatment & 11 & $6 \mathrm{M} / 5 \mathrm{~F}$ & $9.5 \pm 4.3$ & $-1.1 \pm 1.5$ & $0.8 \pm 1.0$ \\
\hline Glucocorticoid treatment & 13 & $6 \mathrm{M} / 7 \mathrm{~F}$ & $11.6 \pm 3.7$ & $-0.3 \pm 1.3$ & $1.1 \pm 1.2$ \\
\hline Juvenile rheumatoid arthritis & 9 & $3 \mathrm{M} / 6 \mathrm{~F}$ & $12.0 \pm 3.2$ & $-2.6 \pm 1.8$ & $1.0 \pm 1.9$ \\
\hline Celiac disease & 13 & $5 \mathrm{M} / 8 \mathrm{~F}$ & $9.5 \pm 3.5$ & $-1.7 \pm 0.8$ & $-0.2 \pm 0.9$ \\
\hline Paucity of intrahepatic bile ducts & 5 & $2 \mathrm{M} / 3 \mathrm{~F}$ & $11.0 \pm 3.3$ & $-2.4 \pm 0.6$ & $-1.3 \pm 0.5$ \\
\hline Autoimmune hepatitis & 8 & $3 \mathrm{M} / 5 \mathrm{~F}$ & $12.8 \pm 4.6$ & $-0.8 \pm 1.1$ & $1.5 \pm 1.1$ \\
\hline Genetic diseases & 9 & $4 \mathrm{M} / 5 \mathrm{~F}$ & $8.8 \pm 3.2$ & $-0.8 \pm 1.9$ & $0.3 \pm 1.2$ \\
\hline Idiopathic juvenile osteoporosis & 7 & $6 \mathrm{M} / 1 \mathrm{~F}$ & $12.4 \pm 2.7$ & $0.7 \pm 0.9$ & $1.9 \pm 1.0$ \\
\hline Disuse osteoporosis & 11 & $10 \mathrm{M} / 1 \mathrm{~F}$ & $11.3 \pm 3.9$ & $-1.3 \pm 1.1$ & $-0.3 \pm 1.8$ \\
\hline$\beta$-Thalassemia major & 10 & $3 \mathrm{M} / 7 \mathrm{~F}$ & $18.4 \pm 4.3$ & $-2.4 \pm 1.2$ & $-0.01 \pm 1.8$ \\
\hline Survivors of acute lymphoblastic leukemia & 8 & $3 \mathrm{M} / 5 \mathrm{~F}$ & $13.5 \pm 4.1$ & $-0.9 \pm 1.6$ & $1.1 \pm 1.8$ \\
\hline Liver transplantation & 3 & $3 \mathrm{~F}$ & $17.0 \pm 2.4$ & $-2.0 \pm 0.2$ & $-0.6 \pm 0.5$ \\
\hline Calcium deficiency & 8 & $4 \mathrm{M} / 4 \mathrm{~F}$ & $9.9 \pm 4.0$ & $-0.4 \pm 1.2$ & $0.6 \pm 1.3$ \\
\hline Nutritional rickets & 4 & $3 \mathrm{M} / 1 \mathrm{~F}$ & $3.5 \pm 0.9$ & $-1.7 \pm 0.9$ & $0.2 \pm 1.0$ \\
\hline X-linked hypophosphatemic rickets & 16 & $6 \mathrm{M} / 10 \mathrm{~F}$ & $7.6 \pm 4.2$ & $-2.5 \pm 1.1$ & $1.6 \pm 1.2$ \\
\hline
\end{tabular}

Data are expressed as mean $\pm \mathrm{SD}$.

* M, males; F, females. 
supplements $(600 \mathrm{IU} / \mathrm{d})$, no patient had received drugs known to alter bone and mineral metabolism in the 6 mo preceding entry into the study.

In patients with idiopathic juvenile osteoporosis diagnosis was made after the exclusion of known causes of osteoporosis in childhood (20). All patients were examined at diagnosis. They were appropriately physically active for their age.

Patients with disuse osteoporosis consisted of severely handicapped children with or without cerebral damage $(n=4$ and $n=7$, respectively). All patients showed extremely reduced mobility. No patient was institutionalized. The patients with cerebral damage received chronic anticonvulsant treatment (phenobarbital or phenytoin) for seizures, and vitamin D supplements $(600-800 \mathrm{IU} / \mathrm{d})$.

Patients with $\beta$-thalassemia major underwent regular transfusions with packed red cells every 3 to $4 \mathrm{wk}$ and iron chelators (desferrioxamine s.c. approximately $40 \mathrm{mg} / \mathrm{kg}$ body wt, 6 times/wk). In addition, two patients received calcium carbonate (elemental calcium 1.0-1.5 g/d) and 1,25-dihydroxyvitamin $\mathrm{D}_{3}(1.5-2.0 \mu \mathrm{g} / \mathrm{d})$ for hypoparathyroidism.

Survivors of acute lymphoblastic leukemia were examined 2-4 y after the completion of therapy. All subjects had received methotrexate and glucocorticoid treatment. Two subjects (one boy and one girl) showed hypergonadotropic hypogonadism as a consequence of the treatment and received replacement therapy (boy, testosterone enanthate, $100 \mathrm{mg}$ intramuscular monthly; girl, conjugated estrogens, $0.6 \mathrm{mg} / \mathrm{d}$ for $24 \mathrm{~d} / \mathrm{mo})$.

Transplanted subjects underwent liver transplantation for primary biliary cirrhosis, caused by severe biliary atresia, from 3 to $11 \mathrm{y}$. All subjects were receiving immunosuppressive therapy with cyclosporin A (2.9-3.2 mg/kg per day) to prevent graft rejection. All subjects had a normal liver and renal function.

Patients with dietary calcium deficiency avoided dairy products for genetically induced lactose intolerance $(n=2)$, cow's milk protein allergy $(n=3)$, or eczema or atopic diseases $(n=$ 3). All patients received calcium supplements such as carbonate (elemental calcium $0.5-1.0 \mathrm{~g} / \mathrm{d}$ ), but compliance with the treatment was poor. In all patients, total calcium intake was less than $50 \%$ compared with the recommended dietary allowance (21) (infants, $n=1,345 \mathrm{mg} / \mathrm{d}$ and $800 \mathrm{mg} / \mathrm{d}$; children, $n$ $=3,332 \pm 36 \mathrm{mg} / \mathrm{d}$ and $1000 \mathrm{mg} / \mathrm{d}$; adolescents, $n=4,378$ $\pm 45 \mathrm{mg} / \mathrm{d}$ and $1200 \mathrm{mg} / \mathrm{d}$, respectively).

Patients with nutritional rickets were examined at diagnosis. Vitamin D deficiency was caused by extremely reduced sunlight exposure without vitamin D supplementation. Three patients were institutionalized from birth: two of these were adopted from East Europe and one was rejected by the parents. One patient lived in a practicing Muslim family and wore concealing clothing when outdoors. All patients had reduced serum 25-OH-D $(19.2 \pm 2.4 \mathrm{nM}, p<0.001)$ and increased serum intact PTH $(142.8 \pm 16.4 \mathrm{ng} / \mathrm{L}$; normal values, $10-60$ $\mathrm{ng} / \mathrm{L} ; p<0.001)$ levels.

Patients with X-linked hypophosphatemic rickets were examined at diagnosis $(n=8)$ or during treatment $(1,25-$ dihydroxyvitamin $\mathrm{D}_{3}, 35-40 \mathrm{ng} / \mathrm{kg}$ per day plus inorganic oral phosphate salts, $70-90 \mathrm{mg} / \mathrm{kg}$ per day, $n=8$ ).
Study design. In all patients $\mathrm{AD}-\mathrm{SoS}$ was assessed at the proximal phalanges of the hand, and the values were compared with sex- and age-reference values by using our own normative data (22). In the majority of patients $(n=120,88.9 \%) \mathrm{CA} / \mathrm{TA}$ ratio was assessed by metacarpal radiogrammetry; the values of patients were compared with sex- and age-reference values by using those reported by Garn et al. (23). In 99 patients (73.3\%), with the exception of patients with X-linked hypophosphatemic rickets, lumbar BMDarea and lumbar BMDvolume by DXA were also assessed. Lumbar BMDarea and lumbar BMDvolume values of patients were compared with sex- and age-reference values by using those reported by Boot et al. (24), which were obtained by the same DXA machinery equipped with the same software as we used. In all patients with X-linked hypophosphatemic rickets radial BMD by single-photon absorptiometry instead of lumbar BMD was measured because they usually have reduced appendicular BMD independent of treatment (25-27) and increased axial BMD $(26,27)$ caused by overabundance of partially mineralized osteoid (26), or a high prevalence of spinal osteosclerosis and enthesopathy $(27,28)$. The radial BMD values were compared with sex- and age-reference values by using our own normative data (29).

In addition, we compared AD-SoS, CA/TA ratio, and lumbar BMD values between patients who had a history of fractures (fractured) and those who had never fractured (fracturefree) in the 6 mo preceding the bone measurements. In all fractured patients severity of injury causing fractures and sites of fractures were recorded.

Consent. Informed consent to perform the study was obtained from the parents and from their son or daughter when his or her chronologic age was younger than $18 \mathrm{y}$ and directly from each patient whose chronologic age was older than $18 \mathrm{y}$. The study was approved by the ethics committee for human investigation of our department.

Assessment of anthropometric findings. Standing height was measured with a wall-mounted stadiometer by one of us. To allow a comparison between different ages and sexes, height was expressed as z score according to Freeman et al. (30). BMI was calculated using the formula weight (kilograms) divided by height (square meters), and the values were expressed as z score according to Cole et al. (31).

Assessment of ultrasound velocity. The device used (DBM Sonic 1200; IGEA, Carpi, Italy) is based on the transmission of ultrasound through the distal end of the first phalangeal diaphysis in the proximity of the condyles (ROI) of the last four fingers of the hand. The condyles at the distal diaphysis provide a convenient point for placing the probes, which is an essential feature for reproducibility of measurements (11). The distal end of the diaphysis of the proximal phalanges contains both cortical and trabecular bone, as well as a small medullary canal; the anatomic ROI is mostly cortical bone (approximately $60 \%$ ) (32). Two 12-mm-diameter transducers on a high precision $( \pm 0.02 \mathrm{~mm})$ caliper, which measures the distance between the two probes, are positioned on the lateral and medial surface of each finger. The medial and lateral surface of the phalanx at the ROI is approximately parallel, hence reducing ultrasound scattering (11). The coupling of the probes with the 
skin is mediated by standard ultrasound gel. The device calculates the speed of sound (meters per second) through the phalanx by measuring the width of the finger (including soft tissues) divided by the time of flight, defined as the time from emitted pulse to received signal considering the signal that reaches a predetermined minimum amplitude value $(2 \mathrm{mV})$ for the first time; thus, the assessed ultrasound velocity is amplitude-dependent (33). Further details are reported elsewhere (22). The final result is the average AD-SoS, expressed as meters per second, over four fingers. In all subjects, AD-SoS was measured in the nondominant hand. The results were calculated as z score by using the formula: measured individual value minus mean normal value for age and sex divided by SD of normal mean. Intra- and interoperator $\mathrm{CV}$, in vivo, was $0.55 \%$ and $0.91 \%$, respectively.

Assessment of cortical bone mass by metacarpal radiogrammetry. A radiograph of the nondominant hand with the hand placed in a position determined by a palm plate was made to measure the CA/TA ratio according to Garn et al. (23). Morphometric measurements were performed at the midshaft of the second metacarpal by an electronic caliper $( \pm 0.02 \mathrm{~mm})$. The second metacarpal bone diaphysis usually has a central longitudinal axis of symmetry, and its cortex is equally thick, often homogeneous, and easily measurable on both the cubital and the radial sides (34). The basic measurements were TW and MW; thereafter, TA $\left(0.785 \times \mathrm{TW}^{2}\right)$, MA $\left(0.785 \times \mathrm{MW}^{2}\right)$, and CA $\left(0.785 \times\left[\mathrm{TW}^{2}-\mathrm{MW}^{2}\right]\right)$ were calculated (23). $\mathrm{CA} / \mathrm{TA}$ ratio was determined to express the proportion of bone in the bone envelope. Thus, CA/TA ratio may be considered to be an indirect method of estimating cortical bone mass (5-9, $23)$. The results were calculated as $z$ score by using the same formula as we used to calculate AD-SoS z score. The CV of TW and MW was obtained from four sets of measurements made at intervals of some days on the same films of 15 different patients. Measurements were performed by the same observer, as suggested $(8,9)$. Intraoperator $\mathrm{CV}$, in vivo, was $1.4 \%$ for TW and $5.1 \%$ for MW according to Virtama and Helela (8) and Dequeker (9).

Assessment of BMD by densitometric techniques. Radial BMD (BMC normalized for bone width, expressed as grams per square centimeter) was measured by single-photon absorptiometry (model 2783; Norland Corp., Atkinson, WI, U.S.A.) at the distal third ( $33 \%$ site) of the nondominant forearm. This ROI of the radius is almost uniformly cylindrical and consists predominantly of cortical bone (approximately 95\%) (35).

Lumbar BMDarea (BMC corrected by the vertebral surface area scanned, expressed as grams per square centimeter) was measured by posteroanterior DXA (Lunar DPX-L/PED; Lunar Radiation Corp., Madison, WI, U.S.A.) in the lumbar spine at L2-L4 level, a site that provides a measure of integral (cortical plus trabecular) bone. The ROI of the DXA scan consists approximately of $50 \%$ cortical and $50 \%$ trabecular bone (35). Indeed, at the ROI the posterior elements of the vertebra are inevitably included in the quantification of BMC; they contain approximately $50 \%$ of the total $\mathrm{BMC}$ of the whole vertebra being primarily compact bone (36). Lumbar BMDvolume (expressed as grams per cubic centimeter) was calculated as $\mathrm{BMC} /$ bone volume. The estimation of L2-L4 bone volume was based on the method proposed by Kroger et al. (3); in this model the lumbar vertebral body was assumed to have a cylindrical shape. The validity of this model was assessed using in vivo volumetric data obtained from magnetic resonance imaging of lumbar vertebrae (37). The bone volume of each vertebral body was calculated as follows: volume $=\pi \times$ $(\text { diameter } / 2)^{2} \times$ height, where diameter $=$ width of vertebral body, and height $=$ height of vertebral body (2). The height and width of vertebral bodies were provided as ancillary DXA-derived data assessed by posteroanterior DXA scans (24, $37,38)$. Although the volume correction is not anatomic, lumbar BMDvolume values provide a better approximation of the true bone density than lumbar BMDarea (2-4). The reference values for lumbar BMDvolume to compare the results of our patients were obtained by using the same formula and the same procedure of calculation as we used (24).

The results of radial BMD, lumbar BMDarea, or lumbar BMDvolume were calculated as $\mathrm{z}$ score by using the same formula we used to calculate $\mathrm{AD}-\mathrm{SoS} \mathrm{z}$ score. The $\mathrm{CV}$, in vivo, was less than $1.5 \%$ and $1.0 \%$ for radial BMD and lumbar $\mathrm{BMD}$, respectively.

Assessment of fracture findings. In all fractured patients severity of injury causing fractures was recorded. The severity of injury was classified as slight, moderate, or severe according to Landin (39). Slight trauma consisted of an injury caused by forces exerted by the injured individual (e.g. falling to the ground from standing on the same level, ball playing, running); moderate trauma consisted of an injury caused by forces connected to height above ground level (e.g. falling from between 0.5 and $3 \mathrm{~m}$ ) or velocities (e.g. falling downstairs, from a bicycle or scooter, from swings or slides); severe trauma included falling from a height exceeding $3 \mathrm{~m}$, all traffic accidents, or being hit by a moving, heavy object. In all patients, fractures caused by a severe trauma were not included in the study. Two fractures of the same bone caused by the same injury were recorded as one fracture. Multiple fractures of the small bones of the hand or foot were recorded as one fracture regardless of the number of fractured bones. The sites of fractures were confirmed by examining the plain radiographs.

Statistical analysis. The results are expressed as median, or mean $\pm \mathrm{SD}$. Comparisons of $\mathrm{AD}-\mathrm{SoS}, \mathrm{CA} / \mathrm{TA}$ ratio, radial $\mathrm{BMD}$, lumbar BMDarea, and lumbar BMDvolume data between patients and reference values, as well as between fractured and fracture-free patients, were assessed by the nonparametric Mann-Whitney test. Simple linear regression analysis by Pearson's formula was performed to determine the associations among $\mathrm{AD}-\mathrm{SoS}, \mathrm{CA} / \mathrm{TA}$ ratio, radial BMD, lumbar BMDarea, and lumbar BMDvolume. Simple and multiple stepwise regression analyses were carried out between AD-SoS (meters per second), CA/TA ratio, radial BMD (grams per square centimeter), lumbar BMDarea (grams per square centimeter), or lumbar BMDvolume (grams per cubic centimeter) and chronologic age (years), height (centimeter), weight (kilograms), or BMI (kilograms per square meter) as independent variables. The relationship between the methods of measuring of bone mineral status was also examined after dividing the obtained values into tertiles according to Foldes et al. (40). A 
$p<0.05$ was considered significant for all statistical analyses. All statistical analyses were carried out using the SPSS for Windows software program, version 9.0 (Statistical Package of Social Sciences, Chicago, IL, U.S.A.).

\section{RESULTS}

AD-SoS. Median and individual values of AD-SoS, expressed as z score, of patients compared with normative data are reported in Figure 1. In all disorders, but not in patients with paucity of intrahepatic bile ducts or liver transplantation, median AD-SoS values were less than $1 \mathrm{SD}$ of normal mean. Only patients with idiopathic juvenile osteoporosis had a median value of AD-SoS less than $2 \mathrm{SD}$ of normal mean. Mean $\mathrm{AD}-\mathrm{SoS}$ values were significantly reduced in all disorders, except for liver transplantation and nutritional rickets.

$\boldsymbol{C A} / \boldsymbol{T A}$ ratio. Median and individual values of $\mathrm{CA} / \mathrm{TA}$ ratio, expressed as z score, of patients compared with normative data are reported in Figure 2. In all disorders median CA/TA ratio values were less than $1 \mathrm{SD}$ of normal mean. Patients receiving anticonvulsants or glucocorticoids, and patients affected by juvenile rheumatoid arthritis, autoimmune hepatitis, idiopathic juvenile osteoporosis, disuse osteoporosis, or $\beta$-thalassemia major had a median value of CA/TA ratio less than $2 \mathrm{SD}$ of normal mean. Mean CA/TA ratio values were significantly reduced in all disorders, except for patients affected by paucity of intrahepatic bile ducts.

Radial BMD or lumbar BMDarea. Median and individual values, expressed as z score, of radial BMD in patients with $\mathrm{X}$-linked hypophosphatemic rickets and lumbar BMDarea in the other examined disorders compared with normative data are reported in Figure 3. Lumbar BMDarea was assessed in only one patient with paucity of intrahepatic bile ducts or nutritional rickets. In all disorders, but not in patients with celiac disease, median BMD values were less than $2 \mathrm{SD}$ of normal mean. Patients treated with glucocorticoids and patients affected by juvenile rheumatoid arthritis, genetic diseases, disuse osteoporosis, $\beta$-thalassemia major, or survivors of acute lymphoblastic leukemia had a mean value of lumbar BMDarea less than $3 \mathrm{SD}$ of normal mean. Mean BMD values were significantly reduced in all disorders.

Lumbar BMDvolume. Median and individual values of lumbar BMDvolume, expressed as z score, of patients compared with normative data are reported in Figure 4. Lumbar BMDvolume was assessed in only one patient with paucity of intrahepatic bile ducts or nutritional rickets. In all disorders median lumbar BMDvolume values were less than $1 \mathrm{SD}$ of normal mean. Patients treated with glucocorticoids, and patients affected by juvenile rheumatoid arthritis, genetic diseases, idiopathic juvenile osteoporosis, disuse osteoporosis, or $\beta$-thalassemia major had a median value of lumbar BMDvolume less than $2 \mathrm{SD}$ of normal mean. In all examined disorders, but not in liver transplantation, mean lumbar BMDvolume values were significantly reduced.

Mean values of AD-SoS, CA/TA ratio, lumbar BMDarea, and lumbar BMDvolume in patients as a whole. Mean values of $\mathrm{AD}-\mathrm{SoS}(n=135), \mathrm{CA} / \mathrm{TA}$ ratio $(n=120)$, lumbar BMDarea $(n=99)$, and lumbar BMDvolume $(n=99)$ in all patients as a whole, expressed as $\mathrm{z}$ score, were significantly reduced $(p<0.0001)$ in comparison with their normal reference values $(-1.7 \pm 1.0,-2.0 \pm 0.9,-3.0 \pm 1.3$, and -1.9 \pm 1.0 , respectively), as well as mean values of radial BMD in patients with $\mathrm{X}$-linked hypophosphatemic rickets (z score, $-2.7 \pm 0.7 ; p<0.0001)$.

Classification of bone measurements into tertiles is reported in Figure 5. Tertile analysis in patients who performed all the bone measurements $(n=95,70.4 \%)$ showed that more than $84 \%, 59 \%$, and $65 \%$ of patients with low tertile AD-SoS fell within the low tertile of $\mathrm{CA} / \mathrm{TA}$ ratio, lumbar BMDarea, and lumbar BMDvolume, respectively. Seventeen patients who had a value of $\mathrm{AD}-\mathrm{SoS}$ within the low tertile also had a value of

\section{Bone and mineral disorders}

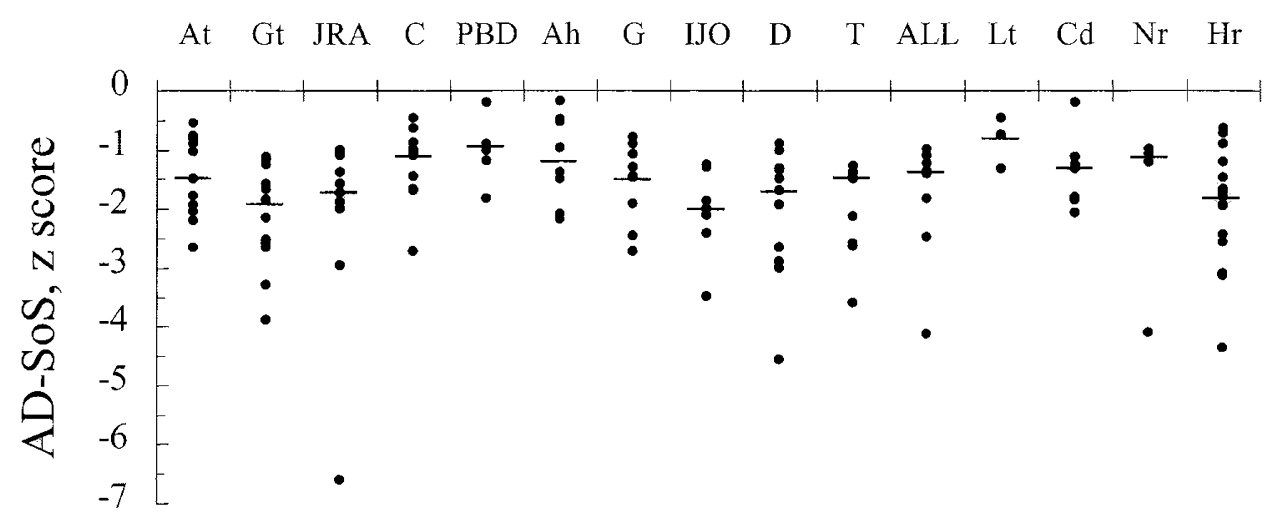

Figure 1. Median and individual values of AD-SoS, expressed as z score, in patients with bone and mineral disorders $(n=135)$ compared with normative data. Mean $\pm \mathrm{SD}$, expressed as $\mathrm{z}$ score, were as follows: $\mathrm{Lt},-0.8 \pm 0.4$ and $\mathrm{Nr},-1.8 \pm 1.3, \mathrm{NS} ; \mathrm{PBD},-1.2 \pm 0.6$ and $\mathrm{Ah},-1.1 \pm 0.7, p<0.01 ; \mathrm{Cd},-1.3 \pm$ $0.5, p<0.001$; At, $-1.5 \pm 0.7, \mathrm{Gt},-2.1 \pm 0.8, \mathrm{JRA},-2.3 \pm 1.6, \mathrm{C},-1.2 \pm 0.6, \mathrm{G},-1.6 \pm 0.6, \mathrm{JJO},-2.0 \pm 0.7, \mathrm{D},-2.1 \pm 1.1, \mathrm{~T},-1.9 \pm 0.7, \mathrm{ALL}$, $-1.8 \pm 1.0$, and $\mathrm{Hr},-1.9 \pm 1.0, p<0.0001$ in comparison with the mean of normative data. Abbreviations: At, chronic anticonvulsant treatment; Gt, glucocorticoids treatment; $J R A$, juvenile rheumatoid arthritis; $C$, celiac disease; $P B D$, paucity of intrahepatic bile ducts; $A h$, autoimmune hepatitis; $G$, genetic diseases; $I J O$, idiopathic juvenile osteoporosis; $D$, disuse osteoporosis; $T, \beta$-thalassemia major; $A L L$, survivors of acute lymphoblastic leukemia; $L t$, liver transplantation; $\mathrm{Cd}$, calcium deficiency; $\mathrm{Nr}$, nutritional rickets; $\mathrm{Hr}$, X-linked hypophosphatemic rickets. 


\section{Bone and mineral disorders}

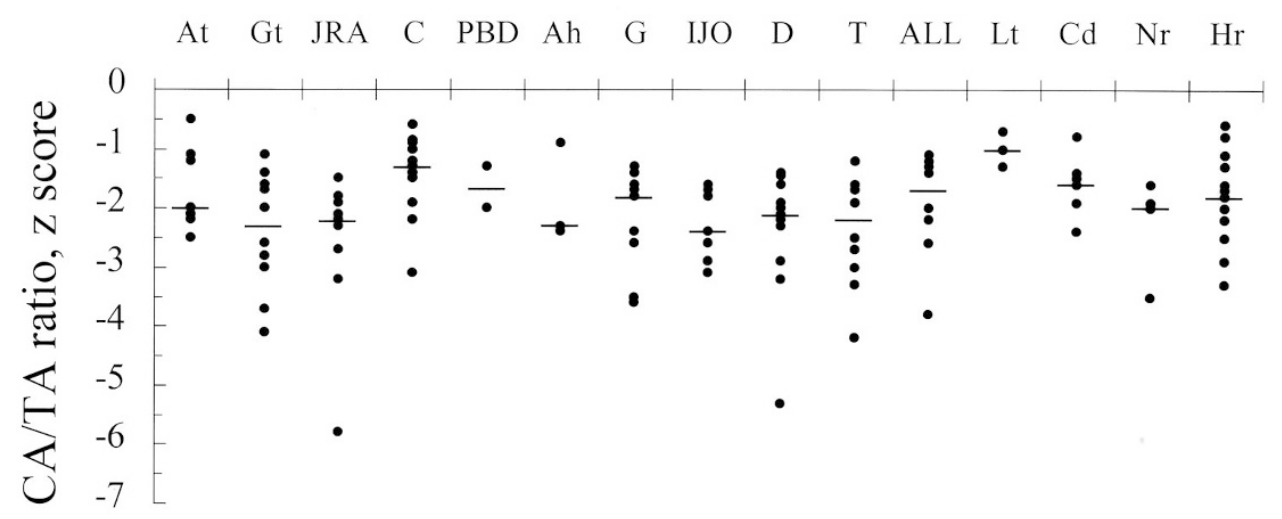

Figure 2. Median and individual values of CA/TA ratio, expressed as z score, in patients with bone and mineral disorders $(n=120)$ compared with normative data. Mean $\pm \mathrm{SD}$, expressed as z score, were as follows: $\mathrm{PBD},-1.7 \pm 0.4$, NS; Ah, $-1.9 \pm 0.7, p<0.04$; Lt, $-1.0 \pm 0.2$ and $\mathrm{Nr},-2.3 \pm 0.7, p<0.01$; At, $-1.7 \pm 0.7$ and ALL, $-2.0 \pm 0.9, p<0.001$; Gt, $-2.4 \pm 0.9$, JRA, $-2.6 \pm 1.2, \mathrm{C},-1.5 \pm 0.7, \mathrm{G},-2.2 \pm 0.8, \mathrm{IJO},-2.3 \pm 0.6, \mathrm{D},-2.4 \pm 1.1, \mathrm{~T},-2.4$ $\pm 0.9, \mathrm{Cd},-1.7 \pm 0.5$, and $\mathrm{Hr},-1.9 \pm 0.8, p<0.0001$ in comparison with the mean of normative data. For abbreviations, see Figure 1.

\section{Bone and mineral disorders}

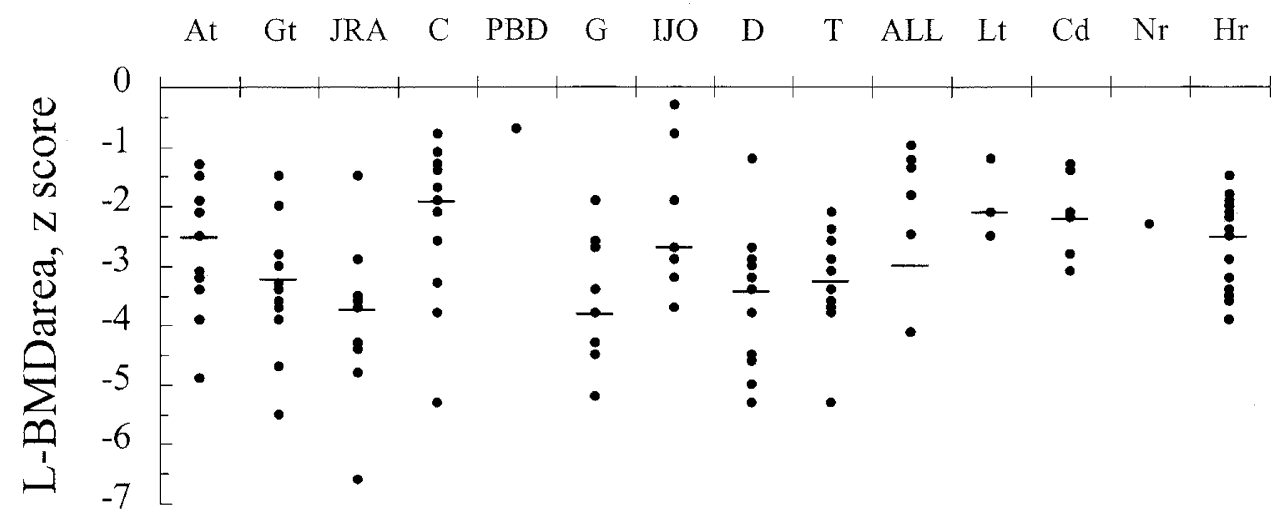

Figure 3. Median and individual values of radial BMD in patients with X-linked hypophosphatemic rickets $(H r, n=16)$ or lumbar BMDarea $(L-B M D a r e a)$ in the other patients with bone and mineral disorders $(n=99)$, expressed as z score, compared with normative data. Mean \pm SD, expressed as z score, were as follows: Lt, $-1.9 \pm 0.5, p<0.02$; ALL, $-2.6 \pm 1.2, p<0.01$; At, $-2.7 \pm 1.1, \mathrm{Gt},-3.3 \pm 1.0, \mathrm{JRA},-3.9 \pm 1.3, \mathrm{C},-2.3 \pm 1.3, \mathrm{G},-3.7 \pm 1.0, \mathrm{IJO},-2.2 \pm 1.2, \mathrm{D},-3.6$ $\pm 1.1, \mathrm{~T},-3.3 \pm 0.9, \mathrm{Cd},-2.2 \pm 0.7$, and $\mathrm{Hr},-2.7 \pm 0.7, p<0.0001$ in comparison with the mean of normative data. For abbreviations, see Figure 1.

$\mathrm{CA} / \mathrm{TA}$ ratio, lumbar BMDarea, and lumbar BMDvolume within their low tertile at the same time.

Correlation among AD-SoS, CA/TA ratio, radial BMD, lumbar BMDarea, and lumbar BMDvolume. A positive relationship was found between $\mathrm{AD}-\mathrm{SoS}$ and CA/TA ratio, lumbar BMDarea, or lumbar BMDvolume, expressed as z score, being the higher correlation coefficient between $\mathrm{AD}-\mathrm{SoS}$ and CA/TA ratio (Fig. 6). CA/TA ratio correlated significantly with lumbar BMDarea $(y=0.492 x-0.601, r=0.67, p<0.0001, n=95)$, or lumbar BMDvolume $(y=0.626 x-0.848, r=0.69, p<$ $0.0001, n=95)$, expressed as z score. Lumbar BMDarea and lumbar BMDvolume, expressed as z score, were significantly correlated ( $y=1.021 x-0.989, r=0.82, p<0.0001, n=99)$. In patients with $\mathrm{X}$-linked hypophosphatemic rickets $\mathrm{AD}-\mathrm{SoS}$ and $\mathrm{CA} / \mathrm{TA}$ ratio, expressed as $\mathrm{z}$ score, correlated with radial $\operatorname{BMD}(y=1.057 x+0.879, r=0.82, p<0.0001, n=16$, and $y=0.649 x-0.147, r=0.63, p<0.01, n=16$, respectively).

There was no correlation between AD-SoS, CA/TA ratio, lumbar BMDarea, or lumbar BMDvolume and chronologic age, height, weight, or BMI in both simple $(r=0.02-0.16$, NS) and multiple regression analyses ( $r=0.19-0.25$, NS).

Sites of fractures and severity of injury in fractured patients. Fifty-two patients (38.5\%) had suffered fractures in the 6 mo preceding the bone measurements (Table 2). The sites of fractures in fractured patients are listed in Table 3. The majority of fractured patients suffered fractures of the upper limb, most commonly occurring in the radial distal metaphysis. Femoral neck was the most common site of fractures in lower limbs. No patient sustained fractures in the ROI for measuring $\mathrm{AD}-\mathrm{SoS}$ or CA/TA ratio.

All but three patients suffered a fracture as a consequence of a slight trauma whereas the remaining patients suffered a fracture caused by a moderate trauma (falling downstairs $n=$ 1 , or from a bicycle $n=2$ ).

Mean values of AD-SoS, CA/TA ratio, lumbar BMDarea, and lumbar BMDvolume in fractured and fracture-free patients. Mean values of $\mathrm{AD}-\mathrm{SoS}, \mathrm{CA} / \mathrm{TA}$ ratio, lumbar BMDarea, and lumbar BMDvolume, expressed as z score, of 


\section{Bone and mineral disorders}

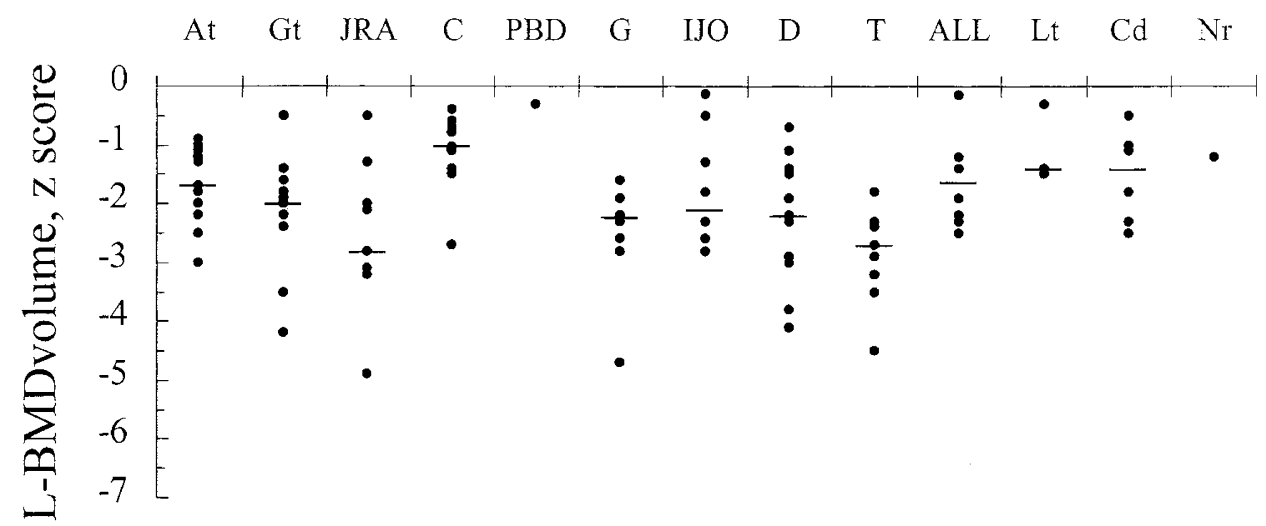

Figure 4. Median and individual values of lumbar BMDvolume ( $L$-BMDvolume), expressed as z score, in patients with bone and mineral disorders $(n=99)$ compared with normative data. Mean $\pm \mathrm{SD}$, expressed as z score, were as follows: $\mathrm{Lt},-1.1 \pm 0.5$, NS; ALL, $-1.6 \pm 0.7, p<0.01$; At, $-1.7 \pm 0.6$, Gt, -2.1 $\pm 0.9, \mathrm{JRA},-2.5 \pm 1.2, \mathrm{C},-1.1 \pm 0.4, \mathrm{G},-2.5 \pm 0.8, \mathrm{IJO},-1.6 \pm 1.0, \mathrm{D},-2.3 \pm 1.0, \mathrm{~T},-2.8 \pm 0.8$, and $\mathrm{Cd},-1.5 \pm 0.7, p<0.0001$ in comparison with the mean of normative data. For abbreviations, see Figure 1.

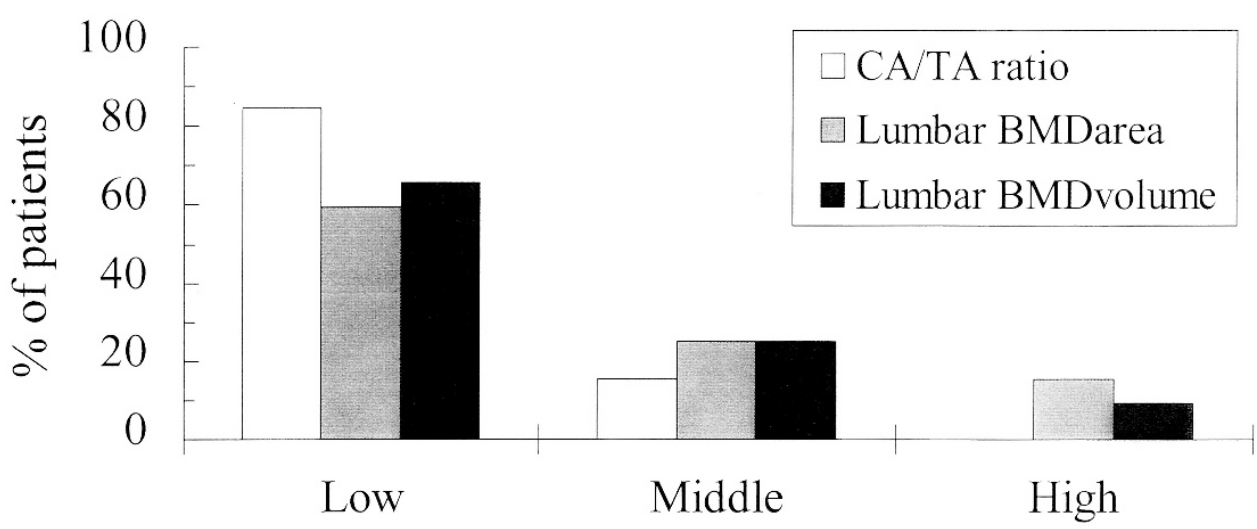

\section{Tertile of measurement values}

Figure 5. Tertile analysis of CA/TA ratio, lumbar BMDarea, and lumbar BMDvolume, expressed as z score, in patients with bone and mineral disorders ( $n$ $=95$ ) whose AD-SoS, expressed as z score, fell within the low tertile.

fractured patients were significantly less than those of fracturefree patients (Fig. 7). In fractured patients, mean values of AD-SoS, CA/TA ratio, lumbar BMDarea, and lumbar BMDvolume were less than $2 \mathrm{SD}$ of normal mean, whereas in fracture-free patients only mean values of lumbar BMDarea were less than $2 \mathrm{SD}$ of normal mean. In fractured patients individual values were less than $1 \mathrm{SD}$ of normal mean in all but one patient for $\mathrm{AD}-\mathrm{SoS}$, in all patients for $\mathrm{CA} / \mathrm{TA}$ ratio, and in all but two patients for both lumbar BMDarea and lumbar BMDvolume (data not shown). Chronologic age, height, weight, and BMI did not differ (NS) between fractured and fracture-free patients (data not shown).

\section{DISCUSSION}

Ultrasound velocity depends on the material properties of the medium through which the ultrasound wave travels, and there is general agreement that ultrasound velocity is influenced by bone density, architecture, and elasticity (10-12). In healthy children and adolescents we showed that phalangeal QUS, in addition to $\mathrm{BMD}$, reflected the architectural organization of growing bone, suggesting that it may be a useful method to assess bone quality in pediatric subjects (22). However, ultrasound velocity measurement does not selectively assess each component of bone tissue influencing ultrasound transmission through bone. Indeed, ultrasound velocity is influenced by structural bone variables, and these variables are also dependent on bone density (41). A recent study in trabecular bone specimens obtained from the proximal phalanx of the forelimb of healthy young pigs showed that ultrasound velocity was related more strictly to BMD than to elasticity (42), confirming previous data in human cadaveric lumbar vertebrae (43).

Our results show that children and adolescents with bone and mineral disorders have reduced mean $\mathrm{AD}-\mathrm{SoS}$ values assessed at the proximal phalanges of the hand, with the exception of patients with nutritional rickets or those who had undergone liver transplantation. A reduced cortical bone mass assessed by metacarpal radiogrammetry was found in all the examined bone and mineral disorders, with the exception of patients with paucity of intrahepatic bile ducts. A reduced lumbar BMDarea was shown in all disorders; whereas a reduced lumbar BMDvolume was found in 


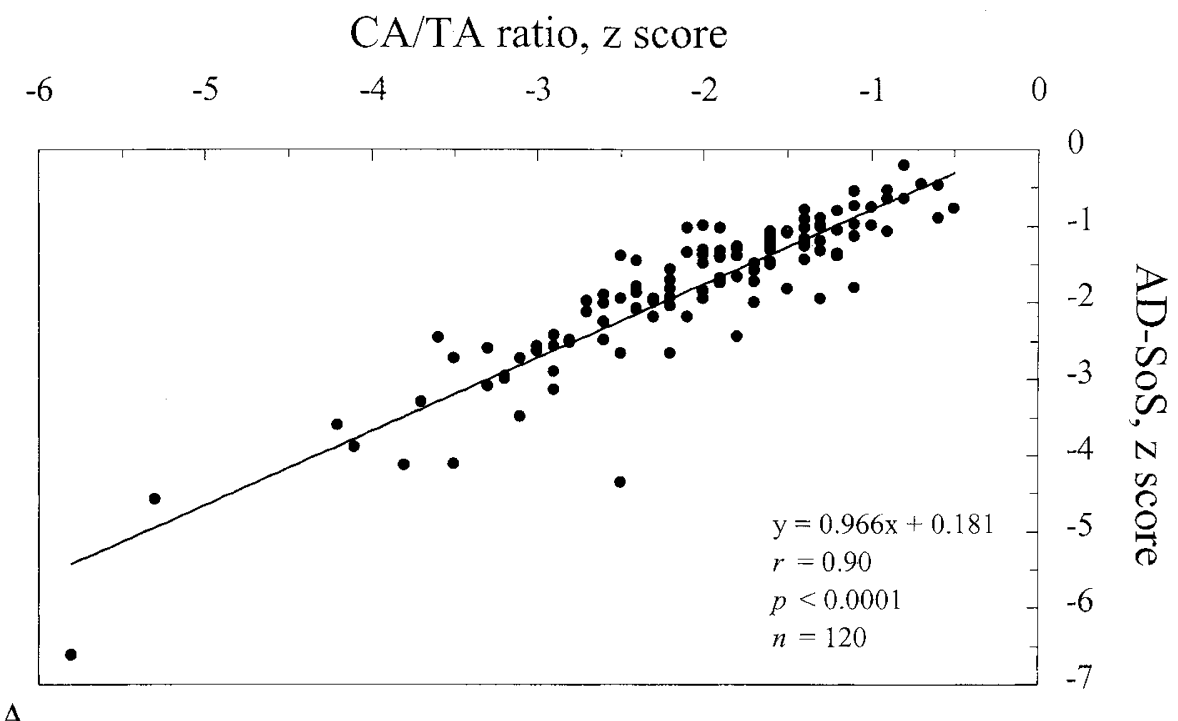

A

Lumbar BMDarea, $\mathrm{z}$ score

$\begin{array}{llllllll}-7 & -6 & -5 & -4 & -3 & -2 & -1 & 0\end{array}$

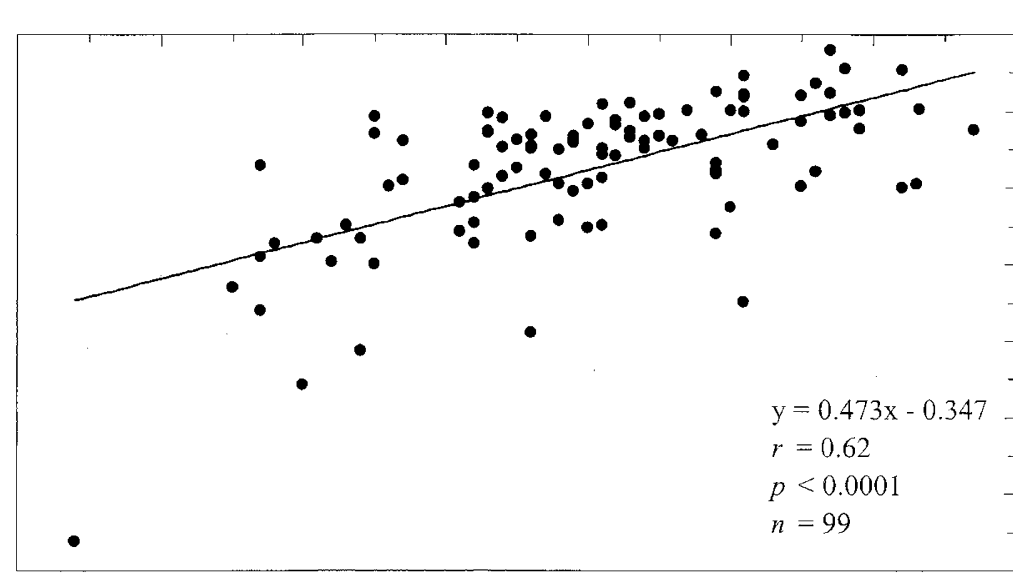

0

$-1$

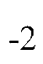

证

$-3$

in

$-4 \mathrm{~N}$

$\bigodot_{0}^{\infty}$

Lumbar BMDvolume, z score
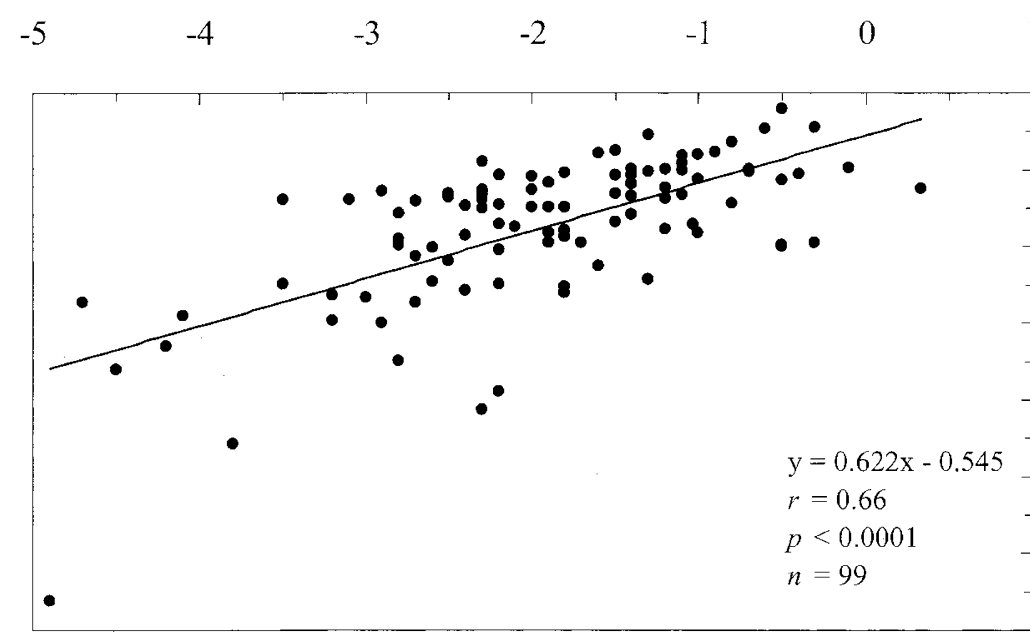

0

$-1$

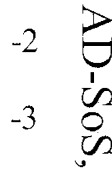

$-4 N$

$-5 \stackrel{0}{\stackrel{0}{0}}$

$-6$

C

Figure 6. Scatter plots of AD-SoS against CA/TA ratio $(A)$, lumbar BMDarea $(B)$, and lumbar BMDvolume $(C)$, expressed as z score, in patients with bone and mineral disorders. Each plot includes the linear regression equation, the correlation coefficient $(r)$, and the number of patients $(n)$. 
Table 2. Fractured and fracture-free patients in examined bone and mineral disorders

\begin{tabular}{lcc}
\hline \multicolumn{1}{c}{ Disorder } & $\begin{array}{c}\text { Fractured } \\
\text { patients } n \\
(\%)\end{array}$ & $\begin{array}{c}\text { Fracture-free } \\
\text { patients } n \\
(\%)\end{array}$ \\
\hline Chronic anticonvulsant treatment & $3(27.3)$ & $8(72.7)$ \\
Glucocorticoid treatment & $7(53.8)$ & $6(46.2)$ \\
Juvenile rheumatoid arthritis & $5(55.6)$ & $4(44.4)$ \\
Celiac disease & - & $13(100)$ \\
Paucity of intrahepatic bile ducts & - & $5(100)$ \\
Autoimmune hepatitis & - & $8(100)$ \\
Genetic diseases & $7(77.8)$ & $2(22.2)^{*}$ \\
Idiopathic juvenile osteoporosis & $7(100)$ & - \\
Disuse osteoporosis & $8(72.7)$ & $3(27.3)$ \\
$\beta$-Thalassemia major & $8(80.0)$ & $2(20.0)$ \\
Survivors of acute lymphoblastic leukemia & $5(52.5)$ & $3(47.5)$ \\
Liver transplantation & - & $3(100)$ \\
Calcium deficiency & $2(25)$ & $6(75)$ \\
Nutritional rickets & - & $4(100)$ \\
X-linked hypophosphatemic rickets & - & $16(100)$ \\
\hline
\end{tabular}

* Marfan syndrome $n=1$, cystic fibrosis $n=1$.

Table 3. Sites of fractures in fractured patients $(n=52)$ with bone and mineral disorders

\begin{tabular}{lrr}
\hline \multicolumn{1}{c}{ Sites of fractures } & $n$ & $\%$ \\
\hline Upper limb & & \\
Humeral diaphysis & 2 & 3.8 \\
Humeral distal metaphysis & 1 & 1.9 \\
Radial diaphysis & 8 & 15.4 \\
Radial distal metaphysis & 15 & 28.8 \\
Hand bones* & 3 & 5.8 \\
All sites & 29 & 55.8 \\
Lower limb & & \\
Femoral neck & 5 & 9.6 \\
Femoral diaphysis & 1 & 1.9 \\
Femoral distal metaphysis & 4 & 7.7 \\
Tibial diaphysis & 3 & 5.8 \\
Tibial distal metaphysis & 4 & 7.7 \\
Peroneal diaphysis & 1 & 1.9 \\
Foot bones & 2 & 3.8 \\
All sites & 20 & 38.5 \\
Other & & \\
Vertebral body $\dagger$ & 3 & 5.8 \\
\hline
\end{tabular}

* The sites of fractures did not involve the ROI for assessing AD-SoS or CA/TA ratio.

$\dagger$ Thoracic spine $n=1$, lumbar spine $n=2$.

all disorders with the exception of patients who had undergone liver transplantation. However, the small number of patients with nutritional rickets, liver transplantation, or paucity of intrahepatic bile ducts may have affected our results. A reduced radial BMD was found in patients with X-linked hypophosphatemic rickets, as expected (25-27).

In all patients as a whole the mean degree of reduction of $\mathrm{AD}-\mathrm{SoS}$ values was similar to that of CA/TA ratio or lumbar BMDvolume, whereas the mean degree of reduction of radial BMD in patients with X-linked hypophosphatemic rickets or lumbar BMDarea in the other bone and mineral disorders was higher than that of $\mathrm{AD}-\mathrm{SoS}, \mathrm{CA} / \mathrm{TA}$ ratio, and lumbar $\mathrm{BMDvolume}$. The degree of reduction in radial BMD or lumbar BMDarea may have been overestimated because the majority of our patients had decreased body height and probably also reduced bone sizes, both affecting these bone mea- surements (2-4). Indeed, body height and peripheral bone width, including radius (44) or vertebral cross-sectional area (45), are closely related. It has been calculated that approximately $6 \%$ of AD-SoS (22) and 19\% of lumbar BMDarea (46) values can be related to bone sizes, whereas the variations in bone sizes would be corrected by CA/TA ratio $(7,9)$. However, it must be considered that the $\mathrm{z}$ score value may not have the same implication with regard to the methodology used to assess bone mineral status or the site(s) for diagnosis. In addition, the reference values of bone mass measurements used for comparison with patients may influence the results (20). The degree of reduction of bone mineral status in bone and mineral disorders we examined could be also influenced by the pathogenetic mechanisms causing osteopenia or osteoporosis and the severity of the disease, but it was difficult to examine the different behavior of the bone measurements according to the cause considering the small number of patients we enrolled for each disorder.

After classification of bone measurements into tertiles, we found that phalangeal QUS identified more than $84 \%$ and $65 \%$ of patients having a value within the low tertile for CA/TA ratio and lumbar BMDvolume, respectively. These data suggest that phalangeal QUS does not identify the same patients with reduced bone mineral status assessed by other techniques, probably because different methods do not measure identical properties of bone tissue. On this matter, it could be that different regions of the growing skeleton can behave differently depending on the structural composition of bone tissue and on the technique being used to assess bone mineral status. Indeed, we showed a moderate correlation between AD-SoS and lumbar BMD, as also reported in osteoporotic women $(13,15)$, and a strong correlation between $\mathrm{AD}-\mathrm{SoS}$ and CA/TA ratio. Moderate correlations between $\mathrm{AD}-\mathrm{SoS}$ and cortical bone mass assessed by metacarpal radiogrammetry were showed in healthy (5) or epileptic women (47), and in adult patients undergoing hemodialysis (48).

The correlation we found between $\mathrm{AD}-\mathrm{SoS}$ and $\mathrm{CA} / \mathrm{TA}$ ratio or radial BMD was higher than that between AD-SoS or CA/TA ratio and lumbar BMDarea or lumbar BMDvolume. This may be accounted for by the high amount of cortical bone with respect to trabecular bone in the peripheral skeleton in comparison with the axial skeleton. These results, and the demonstration in human cadavers that phalangeal QUS was more likely to correlate well with cortical BMD than with trabecular BMD of the distal radius (49), may suggest that cortical bone mass is a main determinant of AD-SoS values. On this matter, a recent study investigating the ultrasound transmission through a cross section of a circular shape of long bone using simulation software (Wave 2000) showed that $\mathrm{AD}-\mathrm{SoS}$ reflected the pathway through cortical bone (50). The influence of cortical thickness on AD-SoS is confirmed by data in vitro $(32,33)$ showing that a reduction of cortical thickness is associated with reduced AD-SoS. Furthermore, in humans it has been demonstrated that $\mathrm{AD}-\mathrm{SoS}$ and relative $\mathrm{CA}$, both measured at the ROI of the middle finger, were significantly correlated $(r=0.74, p<0.0001)$, with the relative CA estimated as $\mathrm{CA} /(\mathrm{CA}+\mathrm{MA})$ ratio, where $\mathrm{CA}$ and MA were assessed by magnetic resonance imaging (50). However, it has 


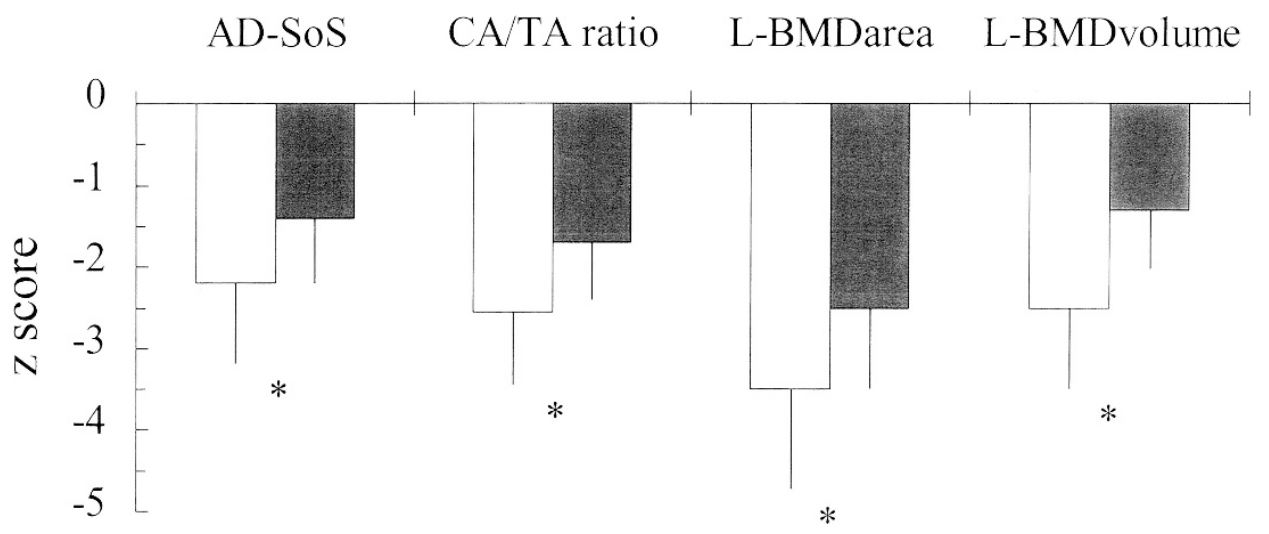

Figure 7. Mean values of AD-SoS, CA/TA ratio, lumbar BMDarea (L-BMDarea), or lumbar BMDvolume (L-BMDvolume), expressed as z score, in fractured (open columns) and fracture-free (filled columns) patients with bone and mineral disorders (AD-SoS: $n=52$ and $n=83$; CA/TA ratio: $n=52$ and $n=68$; lumbar BMDarea or lumbar BMDvolume: $n=51$ and $n=48$, respectively) compared with normative data. ${ }^{*} p<0.0001$ between fractured and fracture-free patients.

also been shown that the amount of trabecular bone in the phalanges of the hand reflects their actual mineral content (8), and that phalangeal QUS reflects bone density and structural changes of trabecular bone in bone specimens of human vertebrae $(43,51)$ and of bovine and rat radius or femur $(11,52$, 53). Similar results are reported in human phalangeal bone (54). Therefore, the reduced AD-SoS values in children and adolescents with bone and mineral disorders probably reflect a decreased BMD and structural changes of both cortical and trabecular bone. Furthermore, it has been shown that phalangeal QUS reflects a bone turnover similar to that of the skeleton as a whole (49), and that early postmenopausal bone loss in women occurs in the metacarpals as well as in the spine (55).

Almost $40 \%$ of patients suffered fractures in the $6 \mathrm{mo}$ preceding bone measurements. All patients with idiopathic juvenile osteoporosis and more than $72 \%$ of patients with genetic disease, disuse osteoporosis, and $\beta$-thalassemia major had suffered fractures, but other bone and mineral disorders were not associated with fractures. However, some factors could have affected our results, such as the time period we considered for assessing the prevalence of fractures, the number of patients, the duration and severity of the disease, or the treatment regimens. In fractured patients, the radial distal metaphysis was the most frequent fracture site, as also reported in healthy children $(39,56)$. It has been shown that the highest prevalence of fractures of the distal radius in healthy children may be related to the fact that the increase in distal radius strength lags behind the increase in mechanical challenges caused by an injury, because metaphyseal cortical thickness does not increase sufficiently (57). This phenomenon may be increased in children with bone and mineral disorders. All but three fractured patients suffered low-energy fractures, suggesting that a main determinant of fractures was an abnormal bone in which the elastic resistance was weakened. In adults, it has been found that the total strength of an osteoporotic bone can be as much as $40 \%$ less than that of a normal bone (58). Therefore in children with bone and mineral disorders, in addition to loading factors (incidence and mechanics of injuries), structural factors affecting bone elasticity, such as changes in trabecular architecture and in cortical thickness, may increase fracture risk (59).
In fractured patients mean values of $\mathrm{AD}-\mathrm{SoS}, \mathrm{CA} / \mathrm{TA}$ ratio, lumbar BMDarea, and lumbar BMDvolume were significantly lower than those of fracture-free patients, with the mean degree of reduction of AD-SoS values being similar to that of CA/TA ratio and lumbar BMDvolume. These results suggest that phalangeal QUS may be a useful tool for evaluating fracture risk in children and adolescents with bone and mineral disorders to a similar extent as metacarpal radiogrammetry and lumbar BMDvolume by DXA. It has been found that phalangeal QUS had a predictive power of fractures similar to DXA in human cadaveric forearms (49) and in osteoporotic women (15). Moreover ultrasound velocity was a stronger independent predictor of the Young's modulus, as assessed by microstructural finite element analysis from microcomputed tomography reconstructions, than BMD measured by DXA in bovine trabecular bone samples (60). A recent study showed that ultrasound velocity by an axial transmission mode, cortical thickness, and BMD by DXA assessed at the proximal phalanges of the hand of human cadavers were significant predictors of wrist fracture load, but only ultrasound velocity was an independent predictor in the model for estimating fracture stress (i.e. fracture load normalized to the total bone area at $15 \%$ of the forearm length) (61). Goulding et al. (62) showed that in young girls a reduction of $1 \mathrm{SD}$ of lumbar BMDvolume, but not of lumbar BMDarea, assessed by DXA, increased the risk (1.3fold) of fracture at any skeletal site during $4 \mathrm{y}$ of follow-up. Similar results were reported in postmenopausal women, showing that a $1 \mathrm{SD}$ reduction in BMD from the age-specific mean population values conferred a 2 - to 3 -fold increase in fracture risk (63). The majority of our patients had median values of lumbar BMDvolume, as well as of AD-SoS and $\mathrm{CA} / \mathrm{TA}$ ratio, less than $1 \mathrm{SD}$ of normal mean, indicating that they may have an increased susceptibility to fractures as a consequence of decreased bone strength.

\section{CONCLUSIONS}

In conclusion, our results showed that $\mathrm{AD}-\mathrm{SoS}$ measured through the distal end of the first phalangeal diaphysis of the last four fingers of the hand was significantly reduced in children and adolescents with bone and mineral disorders. 
Phalangeal QUS was able to discriminate fractured from fracture-free patients to a similar extent as measurement of cortical bone mass assessed by metacarpal radiogrammetry and lumbar BMDvolume assessed by DXA. These data indicate that phalangeal QUS may be a useful tool for assessing bone quality and fracture risk in children and adolescents with bone and mineral disorders, without exposing the patients to a source of radiation. However, it should be considered that any single technique, although predictive of fracture, may underestimate the overall risk in our patients because each technique will identify slightly different, but overlapping, groups of patients as being at risk. Further studies are needed to establish the application of phalangeal QUS in longitudinal studies.

\section{REFERENCES}

1. Wang J, Thornton JC, Horlick M, Formica C, Wang W, Rahn M, Pierson RN 1999 Dual x-ray absorptiometry in pediatric studies. Changing scan modes alters bone and body composition measurements. J Clin Densitom 2:135-141

2. Baroncelli GI, Saggese G 2000 Critical ages and stages of puberty in the accumulation of spinal and femoral bone mass: the validity of bone mass measurements. Horm Res 51(suppl 1):2-8

3. Kroger H, Kotaniemi A, Vainio P, Alhava E 1992 Bone densitometry of the spine and femur in children by dual-energy x-ray absorptiometry. Bone Miner 17:75-85

4. Lu PW, Cowell CT, Lloyd-Jones SA, Briody JN, Howman-Giles R 1996 Volumetric bone mineral density in normal subjects, aged 5-27 years. J Clin Endocrinol Metab $81: 1586-1590$

5. Aguado F, Revilla M, Hernandez ER, Villa LF, Rico H 1996 Behavior of bone mass measurements. Dual energy x-ray absorptiometry total body bone mineral content, ultrasound bone velocity, and computed metacarpal radiogrammetry, with age, gonadal status, and weight in healthy women. Invest Radiol 31:218-222

6. Nielsen SP 2001 The metacarpal index revisited. A brief overview. J Clin Densitom 4:199-207

7. Hyldstrup L, Nielsen SP 2001 Metacarpal index by digital x-ray radiogrammetry. Normative reference values and comparison with dual x-ray absorptiometry. J Clin Densitom 4:299-306

8. Virtama P, Helela T 1969 Radiographic measurements of cortical bone. Variations in a normal population between 1 and 90 years of age. Acta Radiol Suppl 293:1-268

9. Dequeker J 1976 Quantitative radiology: radiogrammetry of cortical bone. Br J Radiol 49:912-920

10. Genant HK, Engelke K, Fuerst T, Gluer C-C, Grampp S, Harris ST, Jergas M, Lang T, Lu Y, Majumdar S, Mathur A, Takada M 1996 Noninvasive assessment of bone mineral and structure: state of the art. J Bone Miner Res 11:707-730

11. Njeh CF, Boivin CM, Langton CM 1997 The role of ultrasound in the assessment of osteoporosis: a review. Osteoporos Int 7:7-22

12. Gregg EW, Kriska AM, Salamone LM, Roberts MM, Anderson SJ, Ferrell RE, Kulle LH, Cauley JA 1997 The epidemiology of quantitative ultrasound: a review of the relationship with bone mass, osteoporosis and fracture risk. Osteoporos Int 7:89-99

13. Hans D, Njeh CF, Genant HK, Meunier P-J 1998 Quantitative ultrasound in bone status assessment. Rev Rhum Engl Ed 65:489-498

14. Reginster JY, Dethor M, Pirenne H, Dewe W, Albert A 1998 Reproducibility and diagnostic sensitivity of ultrasonometry of the phalanges to assess osteoporosis. Int J Gynecol Obstet 63:21-28

15. Wüster C, Albanese C, De Aloysio D, Duboeuf F, Gambacciani M, Gonnelli S, Gluer CC, Hans D, Joly J, Reginster JY, De Terlizzi F, Cadossi R, and The Phalangeal Osteosonogrammetry Study Group 2000 Phalangeal osteosonogrammetry study: agerelated changes, diagnostic sensitivity, and discrimination power. J Bone Miner Res 15:1603-1614

16. Karlsson MK, Duan Y, Ahlborg H, Obrant KJ, Johnell O, Seeman E 2001 Age, gender, and fragility fractures are associated with differences in quantitative ultrasound independent of bone mineral density. Bone 28:118-122

17. Gonnelli S, Cepollaro C 2002 The use of ultrasound in the assessment of bone status J Endocrinol Invest 25:389-397

18. Pedrera JD, Lopez MJ, Canal ML, Costa C, Manas P, Hernandez ER, Rico H 2001 Quantitative phalangeal bone ultrasound is normal after long-term gluten-free diet in young coeliac patients. Eur J Gastroenterol Hepatol 13:1169-1173

19. Pluskiewicz W, Adamczyk P, Drozdzowska B, Szprynger K, Szczepanska M, Halaba Z, Karasek D 2002 Skeletal status in children, adolescents and young adults with endstage renal failure with hemo- or peritoneal dialysis. Osteoporos Int 13:353-357

20. Saggese G, Baroncelli GI, Bertelloni S 2001 Osteoporosis in children and adolescents: diagnosis, risk factors, and prevention. J Pediatr Endocrinol Metab 14:833-859

21. Italian Society for Human Nutrition 1996 Recommended Dietary Allowances for Italian Population. Litotipografia Zesi, Roma, pp 1-181

22. Baroncelli GI, Federico G, Bertelloni S, De Terlizzi F, Cadossi R, Saggese G 2001 Bone quality assessment by quantitative ultrasound of proximal phalanxes of the hand in healthy subjects aged 3-21 years. Pediatr Res 49:713-718

23. Garn SM, Poznanski AK, Nagy JM 1971 Bone measurement in the differentia diagnosis of osteopenia and osteoporosis. Radiology 100:509-518
24. Boot AM, De Ridder MAJ, Pols HAP, Krenning EP, De Muinck Keizer-Schrama SMPF 1997 Bone mineral density in children and adolescents: relation to puberty, calcium intake, and physical activity. J Clin Endocrinol Metab 82:57-62

25. Block JE, Piel CF, Selvidge R, Genant HK 1989 Familial hypophosphatemic rickets: bone mass measurements in children following therapy with calcitriol and supplemental phosphate. Calcif Tissue Int 44:86-92

26. Oliveri MB, Cassinelli H, Bergadà C, Mautalen CA 1991 Bone mineral density of the spine and radius shaft in children with $\mathrm{X}$-linked hypophosphatemic rickets. Bone Miner 12:91-100

27. Baroncelli GI, Bertelloni S, Ceccarelli C, Saggese G 2001 Effect of growth hormone treatment on final height, phosphate metabolism, and bone mineral density in children with X-linked hypophosphatemic rickets. J Pediatr 138:236-243

28. Polisson RP, Martinez S, Khoury M, Harrell RM, Lyles KW, Friedman N, Harrelson JM, Reisner E, Drezner MK 1985 Calcification of entheses associated with X-linked hypophosphatemic osteomalacia. N Engl J Med 313:1-6

29. Saggese G, Federico G, Ghirri P, Cipriani J, Bertelloni S, Baroncelli GI 1986 Bone mineral content in pediatrics: normal values between 2 and 19 years. First Italian data. Minerva Pediatr 38:545-55

30. Freeman JV, Cole TJ, Chinn S, Jones PRM, White EM, Preece MA1995 Cross sectional stature and weight reference curves for the UK, 1990. Arch Dis Child 73:17-24

31. Cole TJ, Freeman JV, Preece MA1995 Body mass index reference curves for the UK, 1990. Arch Dis Child 73:25-29

32. Njeh CF, Richards A, Boivin CM, Hans D, Fuerst T, Genant HK 1999 Factors influencing the speed of sound through the proximal phalanges. J Clin Densitom 2:241-249

33. Cadossi R, Canè V 1996 Pathways of transmission of ultrasound energy through the distal metaphysis of the second phalanx of pigs: an in vitro study. Osteoporos Int 6:196-206

34. Bonnard GD 1968 Cortical thickness and diaphysial diameter of the metacarpal bones from the age of three months to eleven years. Helv Paediatr Acta 5:445-463

35. Genant HK, Faulkner KG, Gluer CC, Engelke K 1993 Bone densitometry: current assessment. Osteoporos Int 1(suppl.):S91-S97

36. Ortoft G, Mosekilde L, Hasling C, Mosekilde L 1993 Estimation of vertebral body strength by dual photon absorptiometry in elderly individuals: comparison between measurements of total vertebral and vertebral body bone mineral. Bone 14:667-673

37. Kroger H, Vainio P, Nieminen J, Kotaniemi A 1995 Comparison of different models for interpreting bone mineral density measurements using DXA and MRI technology. Bone 17:157-159

38. Sievanen H, Kannus P, Nieminen V, Heinonen A, Oja P, Vuori I 1996 Estimation of various mechanical characteristics of human bones using dual energy x-ray absorptiometry: methodology and precision. Bone $18: 17 \mathrm{~S}-27 \mathrm{~S}$

39. Landin LA 1983 Fracture patterns in children. Acta Orthop Scand 54 (suppl 202):1109

40. Foldes AJ, Rimon A, Keinan DD, Popovtzer MM 1995 Quantitative ultrasound of the tibia: a novel approach for assessment of bone status. Bone 17:363-367

41. Njeh CF, Fuerst T, Diessel E, Genant HK 2001 Is quantitative ultrasound dependent on bone structure? A reflection. Osteoporos Int 12:1-15

42. De Terlizzi F, Battista S, Cavani F, Canè V, Cadossi R 2000 Influence of bone tissue density and elasticity on ultrasound propagation: an in vitro study. J Bone Miner Res $15: 2458-2466$

43. Hans D, Wu CY, Njeh CF, Zhao S, Augat P, Newitt D, Link T, Lu Y, Majumdar S, Genant HK 1999 Ultrasound velocity of trabecular cubes reflects mainly bone density and elasticity. Calcif Tissue Int 64:18-23

44. Maresh MM 1961 Bone, muscle and fat measurements. Longitudinal measurements of the bone, muscle and fat widths from roentgenograms of the extremities during the first six years of life. Pediatrics 28:971-984

45. Gilsanz V, Kovanlikaya A, Costin G, Roe TF, Sayre J, Kaufman F 1997 Differential effect of gender on the sizes of the bones in the axial and appendicular skeletons. J Clin Endocrinol Metab 82:1603-1607

46. Baroncelli GI, Bertelloni S, Ceccarelli C, Saggese G 1998 Measurement of volumetric bone mineral density accurately determines degree of lumbar undermineralization in children with growth hormone deficiency. J Clin Endocrinol Metab 83:3150-3154

47. Pluskiewicz W, Nowakowska J 1997 Bone status after long-term anticonvulsan therapy in epileptic patients: evaluation using quantitative ultrasound of calcaneus and phalanges. Ultrasound Med Biol 23:553-558

48. Rico H, Aguado F, Revilla M, Villa LF, Martin J 1994 Ultrasound bone velocity and metacarpal radiogrammetry in hemodialyzed patients. Miner Electrolyte Metab 20:103-106

49. Wu C, Hans D, He Y, Fan B, Njeh CF, Augat P, Richards J, Genant HK 2000 Prediction of bone strength of distal forearm using radius bone mineral density and phalangeal speed of sound. Bone 26:529-533

50. Barkmann R, Lusse S, Stampa S, Sakata S, Heller M, Gluer CC 2000 Assessment of geometry of human finger phalanges using quantitative ultrasound in vivo. Osteoporos Int 11:745-755

51. Nicholson PHF, Haddaway MJ, Davie MWJ 1994 The dependence of ultrasonic properties on orientation in human vertebral bone. Phys Med Biol 39:1013-1024

52. Gluer C-C, Wu CY, Genant HK 1993 Broadband ultrasound attenuation signals depend on trabecular orientation: an in vitro study. Osteoporos Int 3:185-191

53. Rico H, Hernandez ER, Paez E, Seco C, Gervas JJ, Villa LF 2001 Do ultrasound measurements reflect bone microarchitecture rather than bone mass? An in vitro study of the rat femur with the use of ultrasound, densitometry, and histomorphometry. Invest Radiol 36:323-326

54. Wuster C, Heilmann P, Pereira-Lima J, Schlegel J, Anstatt K, Soballa T 1998 Quantitative ultrasonometry (QUS) for the evaluation of osteoporosis risk: reference data for various measurement sites, limitations and application possibilities. Exp Clin Endocrinol Diabetes 106:277-288 
55. Matsumoto C, Kushida K, Yamazaki K, Imose K, Inoue T 1994 Metacarpal bone mass in normal and osteoporotic Japanese women using computed $\mathrm{x}$-ray densitometry. Calcif Tissue Int 54:324-329

56. Lyons RA, Sellstrom E, Delahunty AM, Loeb M, Varilo S 2000 Incidence and cause of fractures in European districts. Arch Dis Child 82:452-455

57. Rauch F, Neu C, Manz F, Schoenau E 2001 The development of metaphyseal cortex Implication for distal radius fractures during growth. J Bone Miner Res 16:1547-1555

58. Sheldon JH 1960 On the natural history of falls in old age. BMJ 2:1685-1690

59. Burr DB, Forwood MR, Fyhrie DP, Bruce Martin R, Schaffler MB, Turner CH 1997 Bone microdamage and skeletal fragility in osteoporotic and stress fractures. J Bone Miner Res 12:6-15
60. Van den Berg JPW, Van Lenthe GH, Hermus ARMM, Corstens FHM, Smals AGH, Huiskes R 2000 Speed of sound reflects Young's modulus as assessed by microstructural finite element analysis. Bone 26:519-524

61. Njeh CF, Wu C, Fan B, Hans D, Fuerst T, He Y, Genant HK 2000 Estimation of wrist fracture load using phalangeal speed of sound: an in vitro study. Ultrasound Med Biol 26:1517-1523

62. Goulding A, Jones IE, Taylor RW, Manning PJ, Williams SM 2000 More broken bones: a 4-year double cohort study of young girls with and without distal forearm fractures. J Bone Miner Res 15:2011-2018

63. Lindsay R, Meunier PJ 1998 Osteoporosis: review of the evidence for prevention, diagnosis and treatment and cost-effectiveness analysis. Osteoporos Int 8(suppl 4):S1-S88 